the nerve and bony canal wall. The reduction in the prevalence of delayed facial palsy reported by Briggs and Potter using ACTH tends to support the suggestion that oedema within the canal may play an important part. ${ }^{3}$ Nevertheless, Fisch found an expanding haematoma in half of explored cases, ${ }^{4}$ and in our patient the known coagulation defect makes it likely that bleeding occurred within the canal. As electrical studies cannot reliably detect denervation in the first 24-72 hours, and since $90^{\circ}$ of delayed onset traumatic facial palsies recover completely, an expectant policy with correction of the coagulopathy is to be preferred.

Neuropathies produced by haemorrhage are rare and are usually associated with haemophilia, when femoral nerve lesions are the most frequent. ${ }^{5}$ Our patient developed signs of peripheral nerve damage in three areas. Although he had mechanical trauma to the region of the brachial plexus and the popliteal fossae, the delayed neural damage is more in keeping with haemorrhage around the nerves. The electromyographic evidence suggested that the lesion in both the facial nerve and the lateral popliteal nerves was neuropraxia and the early recovery confirmed this.

${ }^{1}$ Patten, B, Archives of Neurology, 1969, 21, 381.

2 Potter, J M, and Braakman, R, in Handbook of Clinical Neurology, ed P J Vinken and G W Bryun, vol 24, p 105. Amsterdam, Elsevier, 1976.

${ }^{3}$ Briggs, M, and Potter, J M, British Medical fournal, 1971, 3, 458.

${ }^{4}$ Fisch, V, Laryngoscope, 1974, 84, 2141.

Tallroth, A, Acta Chirurgica Scandinavica, 1939, 17, 195.

(Accepted 17 fanuary 1978)

Ferens Institute of Otolarynogology and Department of Neurologica Studies, The Middlesex Hospital, London W1

I E COLE, FRCS, registrar, ear, nose, and throat department

P D M ELLIS, FRCS, senior registrar, ear, nose, and throat department M J G HARRISON, DM, FRCP, consultant neurologist

\section{Intermittent positive-pressure breathing}

There has been some doubt whether the bronchodilator effect of nebulised salbutamol would be enhanced by intermittent positivepressure breathing (IPPB). We have studied this in a random trial.

\section{Methods and results}

Nebulised salbutamol (10 mg) was given by either Wright's nebuliser or IPPB with a Bennett PR2 ventilator to patients admitted to hospital in status asthmaticus. Ten patients (seven men, three women) of mean age 37 years (SD 19) were studied.

On admission patients recorded a self-assessment of breathlessness on a $250 \mathrm{~mm}$ line (linear analogue self-assessment scale) ${ }^{1}$; the pulse rate was recorded and peak expiratory flow rate (PEFR) measured A standard corticosteroid and fluid replacement regimen was begun and one of the alternative treatments (randomly selected) was given. Five minutes, three hours, and six hours afterwards the measurements were repeated. The alternative method was then used and measurements made at similar intervals. Thereafter the treatment first used was administered four times daily. On the second and third day the measurements were repeated before and after the midday treatment. Volumes of solution nebulised were adjusted so that the same time was taken by each method. All tests of statistical significance were based on Wilcoxon's Rank Sum test, with the order effect being allowed for in the crossover phase of the trial.
Crossover phase-Six patients received Wright's nebuliser first, and four patients received IPPB first. All patients recorded a considerable improvement in symptom score immediately after the first treatment (table) and thereafter showed little change. There was no significant difference between the results of the treatments. The pulse rate dropped after using the Wright's nebuliser and increased after IPPB. The difference in response to the treatments was statistically significant 5 minutes after treatment $(P<0.05)$. Changes in PEFR showed no statistically significant difference between the two methods.

Second phase-After the crossover patients continued treatment by the method used first. For all patients responses on the second and third days of. the trial were similar and have been amalgamated (table). Symptom scores $\overrightarrow{\vec{F}}$ showed a significantly greater increase from the pretrial levels for patients using the Wright's nebuliser $(P<0.05)$. The results from days 2 and 3 again showed a different effect of the two methods on pulse rate. In both groups $\bar{\sigma}$ the pulse rates averaged over days 2 and 3 were lower than the admission $\bar{\omega}$ rates, but this drop was greater in the patients using the Wright's nebuliser $(P<0.05)$. Only one patient showed major changes in pulse rate immediately $\varrho$ after treatment on days 2 and 3: he was in the IPPB group, and the rate rose from 80 to $108 / \mathrm{min}$ and from 88 to $104 \mathrm{~min}$, respectively. PEFR changes showed substantial variation among individuals. Although the rise $\vec{O}$ was higher in the group using the Wright's nebuliser, significance at the $5 \%$ level was not obtained.

\section{Discussion}

Although Webber et $a l^{2}$ found no difference between the bronchodilator effects of salbutamol given by a Wright's nebuliser and given by IPPB (Bird Mark VII ventilator), they conceded that in more : severe asthma IPPB might offer some advantage. The results of our $\vec{\infty}$ study showed no such advantage for IPPB. After the simple nebuliser $\infty$ the pulse rate fell but after IPPB tachycardia was more pronounced, 음 an undesirable effect in patients with severe asthma. Patients claimed $\sigma$ greater improvement with the Wright's nebuliser.

Dolovich et $a l^{3}$ have shown that IPPB produced less penetration and peripheral deposition of radiolabelled aerosol particles than did $\rightarrow$ quiet mouth breathing in patients with severe airways obstruction. Cherniack $^{4}$ and Murray, ${ }^{5}$ reviewing the American experience, $\infty$ concluded that the available data failed to show any advantage of IPPB in patients with chronic obstructive pulmonary disease. Our results suggest that the same is true for severe asthma and indicate that expensive IPPB machines are not a necessary part of nebulised bronchodilator treatment.

We thank Simonsen and Weel for the loan of a Bennett PR2 Ventilator and Mrs S Frost for typing the manuscript.

${ }^{1}$ Aitken, R C B, Proceedings of the Royal Society of Medicine, 1969, 62, 989. 2 Webber, B A, Shenfield, G M, and Paterson, J W, American Review of Respiratory Disease, 1974, 109, 293.

${ }^{3}$ Dolovich, M B, et al, American Review of Respiratory Disease, 1977, 115, 397

${ }^{4}$ Cherniack, R M, American Review of Respiratory Disease, 1974, 110, suppl, p 188.

${ }^{5}$ Murray, J F, American Review of Respiratory Disease, 1974, 110, suppl, p 193.

(Accepted 20 fanuary 1978)

\section{Plymouth General Hospital, Devon}

I A CAMPBELL, MB, MRCP, senior medical registrar (present address: Respiratory Department, Bristol Royal Infirmary)

ALISON HILL, MB, MRCP, senior house officer

H MIDDLETON, MB, MRCP, senior house officer (present appointment: N clinical research fellow, Respiratory Department, Royal Hospital, Sheffield)

M MOMEN, MB, BCHIR, senior house officer

Medical Computing and Statistics Unit, Edinburgh University, Edinburgh EH8 9AG

R J PRESCOTT, MSC, PHD, lecturer

Symptom score, pulse rate, and PEFR (SE in parentheses)

\begin{tabular}{|c|c|c|c|c|c|c|c|c|c|c|c|}
\hline \multirow{3}{*}{ Index } & \multirow{3}{*}{ Order } & \multicolumn{8}{|c|}{ Day 1 -Crossover } & \multirow{2}{*}{\multicolumn{2}{|c|}{ Days 2 and 3}} \\
\hline & & \multicolumn{4}{|c|}{ 1st treatment } & \multicolumn{4}{|c|}{ 2nd treatment } & & \\
\hline & & $\begin{array}{c}\begin{array}{c}\text { Pre- } \\
\text { treatment }\end{array} \\
\end{array}$ & $5 \mathrm{~min}$ & $3 \mathrm{~h}$ & $6 \mathrm{~h}$ & $\begin{array}{c}\text { Pre- } \\
\text { treatment }\end{array}$ & $5 \mathrm{~min}$ & $3 \mathrm{~h}$ & $6 \mathrm{~h}$ & $\begin{array}{c}\text { Pre- } \\
\text { treatment }\end{array}$ & $\begin{array}{c}\text { Post- } \\
\text { treatment }\end{array}$ \\
\hline $\begin{array}{l}\text { Symptom score }(\mathrm{mm}) \\
\text { (higher }=\text { better }) \\
\text { Pulse } \\
\text { rate } / \mathrm{min} \\
\mathrm{PEFR} \\
(1 / \mathrm{min})\end{array}$ & $\left\{\begin{array}{l}\text { IPPB-Wright's } \\
\text { IWright's-IPPB } \\
\text { IPPB-Wright's } \\
\text { Wright's-IPPB } \\
\text { IPPB-Wright's } \\
\text { Wright's-IPPB }\end{array}\right.$ & $\begin{array}{r}50(24) \\
53(16) \\
112(7) \\
118(5) \\
85(22) \\
104(17)\end{array}$ & $\begin{array}{l}83(30) \\
146(16) \\
120(9) \\
112(4) \\
88(23) \\
124(25)\end{array}$ & $\begin{array}{l}103(26) \\
150(17) \\
110(4) \\
107(6) \\
86(25) \\
118(20)\end{array}$ & $\begin{array}{l}104(22) \\
153(18) \\
112(5) \\
93(8) \\
90(21) \\
127(25)\end{array}$ & $\begin{array}{c}104(22) \\
153(18) \\
112(5) \\
93(8) \\
90(21) \\
127(25)\end{array}$ & $\begin{array}{l}111(25) \\
146(16) \\
107(4) \\
112(4) \\
96(22) \\
124(25)\end{array}$ & $\begin{array}{l}89(31) \\
150(17) \\
111(4) \\
107(6) \\
85(15) \\
118(20)\end{array}$ & $\begin{array}{l}85(21) \\
153(18) \\
110(5) \\
93(8) \\
81(13) \\
127(25)\end{array}$ & $\begin{array}{r}90(23) \\
196(23) \\
101(6) \\
91(3) \\
92(25) \\
207(47)\end{array}$ & $\begin{array}{l}113(24) \\
215(17) \\
108(3) \\
90(2) \\
99(32) \\
239(59)\end{array}$ \\
\hline
\end{tabular}

